\title{
Validation of multiplex PCR for detection and differentiation of Salmonellas
}

\author{
Prof. Borys Stegniy, Dr Iryna Gerilovych, Prof. Andrii Zavgorodniy, Anton Gerilovych*, \\ Prof. Vasyl' Vlizlo and Vasyl' Arefiev
}

NSC IECVM, Kharkiv, Ukraine

\section{Objective}

This study aimed to perform interlaboratory testing and clarification of the PCR-based test for its implementation in Ukraine.

\section{Introduction}

Salmonellosis is the zoonotic disease caused by Salmonella bacteria. These are food-borne pathogens, which require improvement of diagnostics and surveillance measures. Prior to implementation of a PCR-based system for monitoring Salmonella, presence and differentiation of the agent was validated under Office International Epizootical (O.I.E.) requirements.

\section{Methods}

The PCR-based detection technique for five Salmonella species was tested under O.I.E. requirements, to determine specificity, sensitivity, and repeatability. Primers were calculated by OLIGO software and produced with HPLC purification. Amplification was conducted by a T3000 Biometra PCR-machine. Testing was performed on a panel of five basic agents: Salmonella enterica ser. Enteritidis, Salmonella ser. Typhimurium, Salmonella ser. Typhi, Salmonella ser. Dublin, Salmonella ser. Gallinarum-Pullorum

\section{Results}

The testing panel included positive samples as controls, containing virus at a concentration of $10^{-1}-10^{7} \mathrm{PFU} / \mathrm{ml}$ ( $\mathrm{n}=5$ for each species). Artificially contaminated clinical materials were also used as positive controls $(n=5)$. Uninfected clinical materials $(n=20)$ were used as negative controls. Samples contaminated with E.coli, Mycobacteria spp. were used to test the platform's ability to differentiate between bacterial genus. Testing determined the overall PCR protocol as 89 $\%$ sensitive, $98 \%$ specific (artificial reactions were observed) and repeatable. These results allowed for the recommendation that the testing technique be implemented in laboratory practice in Ukraine. Furthermore, specific guidelines for performing the test have been developed

\section{Conclusions}

We have validated the PCR-based protocol for indication of Salmonella genus agents and identification of its basic agents $S$. Enteritidis, $S$. Typhimurium, $S$. Typhi, $S$. Dublin, $S$. GallinarumPullorumon that recognized it to be sensitive, specific, and repeatable and able to be implemented in the laboratory practice for food safety control.

\section{Keywords}

multiplex PCR; Salmonella; detection

\section{*Anton Gerilovych}

E-mail: antger@rambler.ru 